Research

Open Access

\title{
Kidney retrieval after sudden out of hospital refractory cardiac arrest: a cohort of uncontrolled non heart beating donors
}

\author{
Fabienne Fieux ${ }^{1}$, Marie-Reine Losser ${ }^{1}$, Eric Bourgeois ${ }^{1}$, Francine Bonnet ${ }^{1}$, Olivier Marie ${ }^{1}$, \\ François Gaudez², Imad Abboud ${ }^{3}$, Jean-Luc Donay4, France Roussin ${ }^{5}$, François Mourey5, \\ Frédéric Adnet ${ }^{6}$ and Laurent Jacob ${ }^{1}$
}

\author{
1'Department of Anesthesia and Critical Care, Hôpital Saint-Louis, Assistance Publique-Hôpitaux de Paris, Université Paris-7 Diderot, 1 Avenue Claude \\ Vellefaux, 75010 Paris, France \\ 2Department of Urology, Hôpital Saint-Louis, Assistance Publique-Hôpitaux de Paris, Université Paris-7 Diderot,1 Avenue Claude Vellefaux, 75010 \\ Paris, France \\ ${ }^{3}$ Department of Nephrology, Hôpital Saint-Louis, Assistance Publique-Hôpitaux de Paris, Université Paris-7 Diderot,1 Avenue Claude Vellefaux, \\ 75010 Paris, France \\ ${ }^{4}$ Department of Microbiology, Hôpital Saint-Louis, Assistance Publique-Hôpitaux de Paris, Université Paris-7 Diderot,1 Avenue Claude Vellefaux, \\ 75010 Paris, France \\ 5 Organ Transplant Coordination Team, Hôpital Saint-Louis, Assistance Publique-Hôpitaux de Paris, Université Paris-7 Diderot, 1 Avenue Claude \\ Vellefaux, 75010 Paris, France \\ ${ }^{6}$ Department Samu 93, Hôpital Avicenne, Assistance Publique-Hôpitaux de Paris, Université Paris-13, 125, rue de Stalingrad, 93000 Bobigny, France \\ Corresponding author: Laurent Jacob, laurent.Jacob@sls.aphp.fr
}

Received: 8 May 2009 Revisions requested: 1 Jul 2009 Revisions received: 1 Jul 2009 Accepted: 28 Aug 2009 Published: 28 Aug 2009

Critical Care 2009, 13:R141 (doi:10.1186/cc8022)

This article is online at: http://ccforum.com/content/13/4/R141

(C) 2009 Fieux et al.; licensee BioMed Central Ltd.

This is an open access article distributed under the terms of the Creative Commons Attribution License (http://creativecommons.org/licenses/by/2.0), which permits unrestricted use, distribution, and reproduction in any medium, provided the original work is properly cited.

\begin{abstract}
Introduction To counter the shortage of kidney grafts in France, a non heart beating donor (NHBD) program has recently been implemented. The aim of this study was to describe this pilot program for kidney retrieval from "uncontrolled" NHBD meaning those for whom attempts of resuscitation after a witnessed outof-hospital cardiac arrest (CA) have failed (Maastricht 1 and 2), in a centre previously trained for retrieval from brain dead donors.

Methods A prospective, monocentric, descriptive study concerning NHBD referred to our institution from February 2007 to June 2008. The protocol includes medical transport of refractory $\mathrm{CA}$ under mechanical ventilation and external cardiac massage, kidney protection by insertion of an intraaortic doubleballoon catheter (DBC) with perfusion of a hypothermic solution, kidney retrieval and kidney preservation in a hypothermic pulsatile perfusion machine.

Results 122 potential NHBD were referred to our institution after a mean resuscitation attempt of 35 minutes (20-95). Regarding the contraindications, 63 were finally accepted and 56 had the DBC inserted. Organ retrieval was performed in 27 patients (43\%) and 31 kidneys out of the 54 procured $(57 \%)$ have been transplanted. Kidney transplantation exclusion was related to family refusal ( $n=15$ ), past medical history, time constraints, viral serology, high vascular ex vivo resistance of the graft and macroscopic abnormalities. The 31 kidneys exhibited an expected high delayed graft function rate (92\%). Despite these initial results transplanted kidney had good creatinine clearance at six months $(66 \pm 24 \mathrm{ml} / \mathrm{min})$ with a $89 \%$ graft survival rate at six months.

Conclusions This study shows the feasibility and efficacy of an organ procurement program targeting NHBD allowing a $10 \%$ increase in the kidney transplantation rate over 17 months. With a six months follow-up period, the results of transplanted kidney function were excellent.
\end{abstract}

BDD: brain dead donors; CPR: cardiovascular pulmonary resuscitation; DBC: double balloon catheter; ECM: external cardiac massage; HBD: heart beating donors; HCV: hepatitis C virus; HTLV1: human lymphocytes T virus; ICU: intensive care unit; NHBD: non heart beating donors; SAMU: service d'aide medicale et d'urgence. 


\section{Introduction}

Given that the healthcare policies regarding end-stage kidney failure in western countries are for less restrictive criteria for entering the kidney transplant list and increasing indications to treat end-stage kidney failure, there is a worsening imbalance between needs and availability of kidneys from cadaver donors. Despite well-functioning organ retrieval programs from brain dead donors (BDD) and living-related donors, the waiting list has lengthened over the years [1].

Organ transplantation programs from non heart beating donors (NHBD) have been implemented in many western countries [2-5], as well as more recently in France [6]. In contrast to many other countries, this organ retrieval program exclusively concerns uncontrolled donors [7] after sudden outof-hospital refractory cardiac arrest.

This prospective, single-centre, descriptive study reports the first data from a cohort of uncontrolled NHBD referred to our Hôpital Saint-Louis from February 2007 to June 2008.

\section{Materials and methods}

A nationwide procedure for kidney retrieval from NHBD was organised by a committee of experts (prehospital emergency, intensive care and transplantation teams). NHBD are classified based on the Maastricht criteria [7] depending on whether cardiopulmonary function ceases spontaneously in the absence (Maastricht 1) or presence (Maastricht 2) of advanced life support or in a BDD (Maastricht 4), or after a medical decision to withdraw life-sustaining therapy from a hospitalised patient (Maastricht 3). This classification in fact opposes 'uncontrolled NHBD' which are patients in whom attempts of resuscitation after a sudden cardiac arrest have failed (Maastricht 1 and 2 categories) and 'controlled NHBD' (Maastricht 3). In France, the procedure excluded Maastricht 3 donors [6].

The procedure was established under the authority of the Agence de la biomédecine and was conducted in compliance with the Helsinki declaration. It was approved by the Ethics Committee of the Agency (22 June, 2004) and by the National Academy of Medicine [8]. The program for kidney retrieval from NHBD that was initiated in our institution in 2006 (Hôpital Saint-Louis, a tertiary teaching hospital, Assistance Publique Hôpitaux de Paris, France) was in strict agreement with the national protocol enacted by the Agence de la biomédecine. In this protocol, next of kin approval for organ donation was obtained prior to any inclusion of the patient in the procedure of organ retrieval. Our observational study did not require any additional intervention and subsequently no further consent from next of kin was requested [9]. The Agence de la biomédecine undertook a national census of these donors in order to provide in parallel an independent longitudinal follow up.

\section{Patients and protocol of care}

The protocol of care is fully described and timing limits are defined in Figure 1. Patients with out-of-hospital cardiac arrest were handled on site by the Fire Departments of Paris and suburbs for basic life support while the emergency medical services (such as service d'aide medicale et d'urgence (SAMU) from the departments 93, 95, 75, 92, 94 and 91) provided advanced life support $[10,11]$. These procedures were in accordance with the standard guidelines for cardiovascular pulmonary resuscitation (CPR) $[12,13]$. These cardiac arrests had to be witnessed to ascertain the time of collapse.

Upon contact with our institution, these patients were screened for eligibility by the coordination team according to demographic data and past medical history. Exclusion criteria are described in Figure 1. When the patients met the inclusion criteria, they were referred to our institution under mechanical ventilation and continuous external cardiac massage (ECM) machine (Autopulse, Zoll ${ }^{\circledR}$, Chelmsford, MA, USA). Upon arrival, body temperature and end-tidal carbon dioxide were recorded. ECM was discontinued and echocardiogram was recorded over five minutes to check the absence of any spontaneous cardiac or haemodynamic activity. Death was certified in accordance with legal requirements [9] stating that the patient was unresponsive to nociceptive stimuli, showed no spontaneous motor activity, no respiratory effort, with an absence of brainstem reflexes. The automated National Registry for organ donation refusal was consulted.

Standard blood work was then performed as a conventional prerequisite for donation: type and screen, human leukocyte antigen typing and toxicology tests. Viral serologies were sent to the reference laboratory. In addition, blood cultures were performed in most patients and were analysed in the Microbiology Department. The blood culture results were compared with the occurrence of infections in recipients within the initial 15 postoperative days.

The possible aetiologies for cardiac arrest were investigated when possible (medical history, last symptoms, post mortem clinical examination, radiological or biological examination, autopsy).

\section{Kidney protection protocol}

An intraaortic double-balloon catheter (DBC) and a venous vent were surgically inserted via an incision in the right side of the groin. After injection of $1.5 \mathrm{M} \mathrm{U}$ streptokinase, the arterial inlet was perfused with a fourth generation heparinised (5000 $\mathrm{U} / \mathrm{I})$ preservation solution (IGL- ${ }^{\circledR}$, Institut Georges Lopez, Saint-Didier-au-Mont-d'Or, France) at a rate of 20 litres within 180 minutes. After kidney retrieval, preservation protocol consisted in hypothermic ( 1 to $4^{\circ} \mathrm{C}$ ) pulsatile perfusion over eight hours in KPS-1 ${ }^{\circledR}\left(\right.$ Lifeport $^{\circledR}$, Organ Recovery System, Des Plaines, IL, USA). The organ preservation solution used in this device was provided by the manufacturer (UW solution, KPS- 


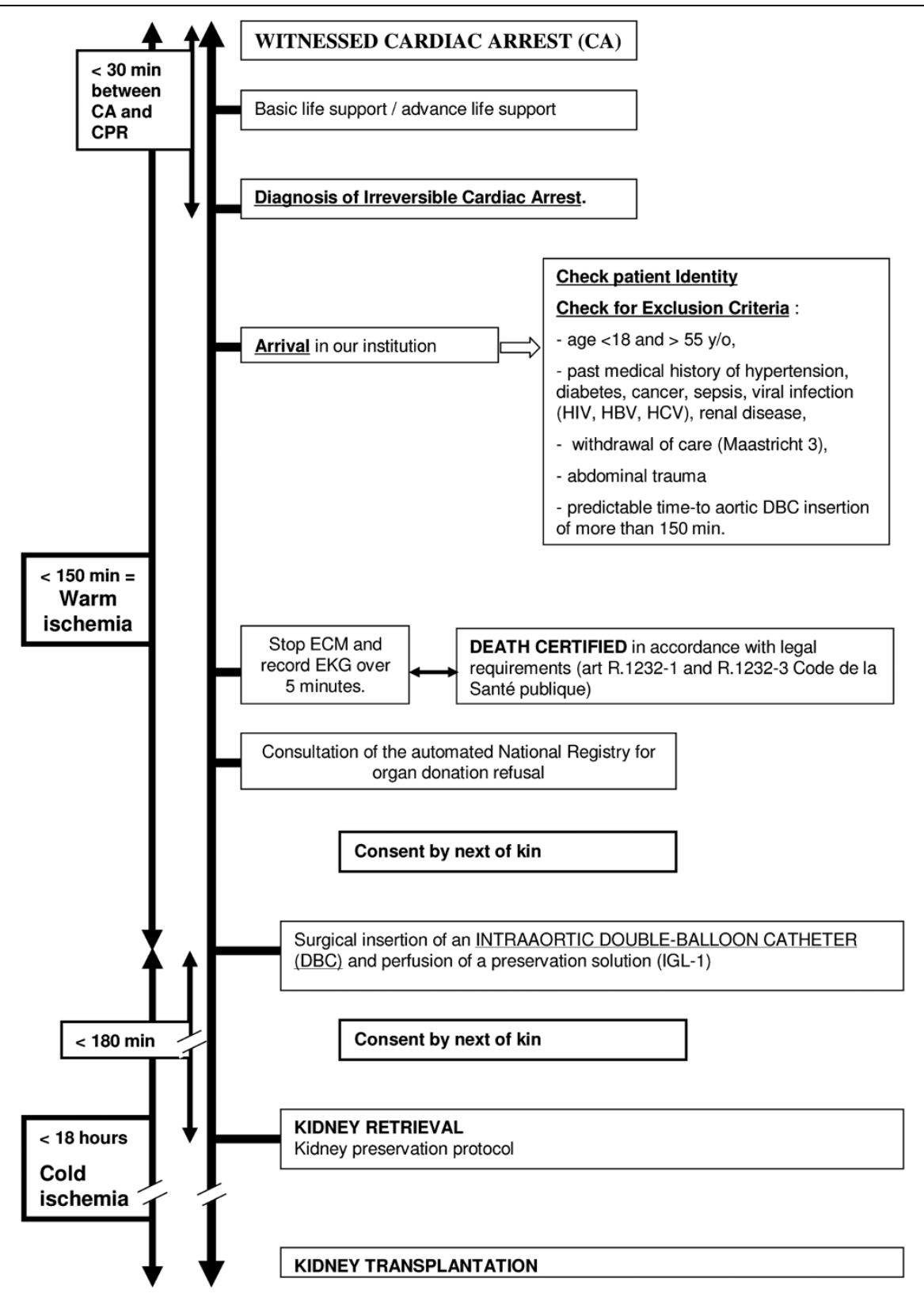

Protocol of care concerning non heart beating donors. Timings, exclusion criteria and protocol steps are described. The time between collapse and cardiopulmonary resuscitation (CPR) initiation had to be less than 30 minutes. The duration of CPR could not be less than 30 minutes. The time between collapse and intraaortic double balloon catheter (DBC) insertion had to be less than 150 minutes, defining warm ischaemia (WI). The time between DBC insertion and kidney retrieval had to be less than 180 minutes, while the kidney had to be transplanted within 18 hours after IGL-1 infusion initiation (cold ischaemia). $\mathrm{HBV}=$ hepatitis $\mathrm{B}$ virus; $\mathrm{HCV}=$ hepatitis $\mathrm{C}$ virus.

$\left.1^{\circledR}\right)$. The organ viability was assessed by measuring the ex vivo intrarenal vascular resistance [14,15]. Intrarenal vascular resistance had to be lower than $0.28 \mathrm{mmHg} / \mathrm{mL} / \mathrm{min}$. Kidneys with high initial resistance were transplanted if it normalised after one hour of pulsatile perfusion. A graft biopsy was performed, but the results were not available before the transplantation.

\section{Kidney transplantation criteria and protocol}

Inclusion criteria for organ recipients were: age less than 60 years, no immunisation and signed informed consent (especially for the risk of delayed kidney function). A different waiting list had been opened for patients willing to join this NHBD program while remaining on the standard BDD list. Postoperative care and follow-up was standardised by the Nephrology 
Transplant Unit. Prophylactic antibiotic therapy with amoxicillin/clavulanic acid was administered for five days after transplantation and a routine check for infections was performed as per protocol. Immunosuppressive therapy used rabbit antihuman thymocyte globulin (thymoglobulins) and steroids for induction, mycophenolate mofetil and cyclosporine for maintenance. Delayed graft function was defined as the need for dialysis during the first week after transplantation with subsequent recovery of renal function. Data were expressed as mean \pm standard deviation or as median (range).

\section{Results Cohort description}

From 1 February 2007 to 30 June 2008, 122 refractory cardiac arrests were screened in our institution. The demographic data of these potential donors showed mostly men (80\%), with a mean age of $41.6 \pm 11.6$ years. Cardiac arrest occurred either at home (52\%), outdoors $(30 \%)$ or at work $(16 \%)$. Among these, 59 (48.4\%) did not meet inclusion criteria as shown in Figure 2. The main organisational problems were an overbooked intensive care unit (ICU) or surgeon unavailability $(n=8)$. Finally, 63 eligible NHBD (52\%) were accepted for organ retrieval. Their main demographic and clinical characteristics are summarised in Table 1.

Figure 2

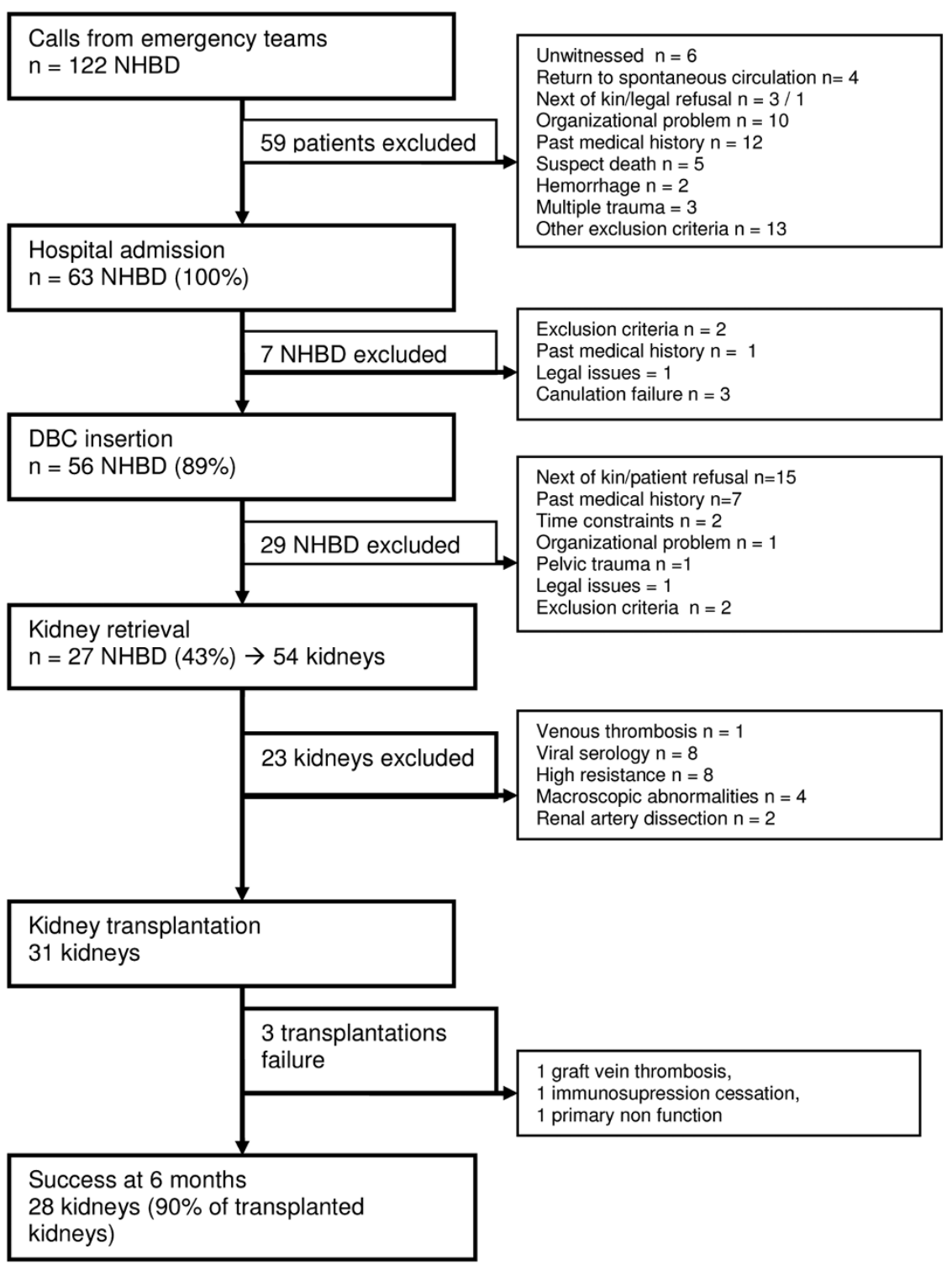

Study profile of non heart beating donors. $\mathrm{DBC}=$ double balloon catheter; NHBD $=$ non heart beating donor. 
Table 1

Demographic, clinical and resuscitation characteristics of non heart beating donors admitted to the authors' institution $(n=63)$

\begin{tabular}{|c|c|}
\hline Male sex - n (\%) & $54(86 \%)$ \\
\hline Age - years & $41 \pm 10$ \\
\hline \multicolumn{2}{|l|}{ Location of cardiac arrest - \% } \\
\hline Home & $52.4 \%$ \\
\hline Outdoors & $30.2 \%$ \\
\hline Workplace & $15.8 \%$ \\
\hline Psychiatric hospital & $1.6 \%$ \\
\hline Maastricht $1 / 2-\mathrm{n}(\%)$ & $54(86 \%) / 9(14 \%)$ \\
\hline CPR performed by bystanders (\%) & $39 \%$ \\
\hline Automated external defibrillation by emergency medical technicians & $37 \%$ \\
\hline Temporary return to spontaneous circulation during advanced life support $-\mathrm{n}(\%)$ & $5(8 \%)$ \\
\hline Duration of spontaneous circulation - minute $( \pm S D)$ & $11 \pm 7$ \\
\hline End-Tidal carbon dioxide at admission $(n=31)-\mathrm{mmHg}$ & $13 \pm 12$ \\
\hline Temperature at admission $-{ }^{\circ} \mathrm{C}$ & $33 \pm 2$ \\
\hline Interval between phone SAMU call to ICU admission - minutes & $48(13-120)$ \\
\hline \multicolumn{2}{|l|}{ Interval (minutes median (min-max)) from collapse } \\
\hline To phone call from bystanders to the advanced life support & $0(0-28)$ \\
\hline To external cardiac massage & $5(0-30)$ \\
\hline To CPR for basic life support & $10(1-40)$ \\
\hline To CPR for advanced life support & $18(0-56)$ \\
\hline To discontinuation of unsuccessful CPR & $35(20-95)$ \\
\hline To departure from the site & $61(35-130)$ \\
\hline To arrival at our hospital & $105(65-163)$ \\
\hline To aortic catheter placement & $144(105-185)$ \\
\hline Cold ischaemia (DBC insertion to transplantation)-hours median (min-max) & 12 h 52 ( 8 h $30-18$ h 00) \\
\hline Interval from aortic catheter placement to retrieval - minute median (min-max) & $175(110-225)$ \\
\hline
\end{tabular}

Data expressed as mean \pm standard deviation (SD) unless stated otherwise.

$\mathrm{CPR}=$ cardiopulmonary resuscitation; $\mathrm{DBC}=$ double balloon catheter; $I \mathrm{IU}=$ intensive care unit.

\section{NHBD procedure}

Thirty seven (59\%) cardiac arrests occurred during the day time ( 8 am to $8 \mathrm{pm}$ ) and 26 during night duty (41\%). Pre-hospital resuscitation is described in Table 1. External cardiac massage was performed within 5 ( 0 to 30 ) minutes, while automated external defibrillator was activated in 37\% of the cases. Once the advanced cardiac life support team was on site, $17(27 \%)$ patients presented with ventricular fibrillation. Five patients recovered a transient spontaneous cardiac activity for a mean duration of $11 \pm 7$ minutes. The mean interval to arrival at our institution after acceptance of NHBD was $53 \pm$ 23 minutes. Among these $63 \mathrm{NHBD}$, aortic DBC was inserted in 56 NHBD (Figure 2). However, on retrospective analysis, time limit for $\mathrm{DBC}$ insertion exceeded the protocol requirement in 12 donors (21\%) for a mean interval of $12 \pm 11$ min- utes. Among these latter donors, 12 kidneys were retrieved and 6 were finally transplanted. Between aortic catheter insertion and kidney retrieval, 175 minutes (110 to 225) elapsed (Table 1). Thus, the interval exceeded 180 minutes in 6 patients $(22 \%)$ for a mean period of $23 \pm 19$ minutes. Among those 12 kidneys, 5 were not transplanted due to positive HIV serology or high intra-renal ex vivo resistance.

\section{Cause of cardiac arrest}

The probable or confirmed aetiologies of cardiac arrest are listed in Table 2. The aetiology was obvious for traumatic cases, some myocardial infarctions, aortic dissection during organ retrieval and when the post mortem medical examination could be performed. Thirteen autopsies were carried out. Seven were ordained by the legal authorities (access to the 
Table 2

\begin{tabular}{lll}
$\begin{array}{l}\text { Death aetiologies of sudden cardiac arrest in } 63 \text { non heart } \\
\text { beating donors }\end{array}$ & Confirmed & Probable \\
\hline Cause & $13(20.6 \%)$ & \\
\hline Trauma & $6(9.5 \%)$ & $14(22.2 \%)$ \\
Cardiac cause & $4(6.3 \%)$ & $2(3.2 \%)$ \\
Stroke & $2(3.2 \%)$ & $1(1.6 \%)$ \\
Aortic dissection & $2(3.2 \%)$ & \\
Hanging & & $1(1.6 \%)$ \\
Pancreatitis & & $1(1.6 \%)$ \\
Hyperkalaemia & $1(1.6 \%)$ & \\
Stab wound & $1(1.6 \%)$ & \\
Gastrointestinal bleeding & $1(1.6 \%)$ & \\
Meningitis & $1(1.6 \%)$ & \\
False passage & $13(20.6 \%)$ \\
Unknown &
\end{tabular}

Unknown cause was defined when clinical examination or biological data were negative and in the absence of prodromes, medical history or evidence from relatives.

results was subsequently denied) and six medical autopsies were accepted by the surrogate decision makers. In four cases, autopsy provided diagnosis: two myocardial infarctions, one gastrointestinal haemorrhage secondary to a gastric ulcer and one mitral prolapse possibly responsible for sudden death. For the two remaining patients, the post mortem examination was negative.

Blood alcohol was positive in $11 \mathrm{NHBD}$, with 6 patients under $1 \mathrm{~g} / \mathrm{l}$ and 5 with a higher level ranging from 1.24 to $3.47 \mathrm{~g} / \mathrm{l}$. Four eligible donors had positive viral serology (rapid technique) contraindicating organ transplantation at first analysis (HIV, human lymphocytes T virus (HTLV) 1, hepatitis $C$ virus $(\mathrm{HCV})$ ). Only one HIV infection and one HCV infection were subsequently confirmed.

Blood cultures were performed in $44 \mathrm{NHBD}$, of which 30 were positive $(68 \%)$. The origin of the isolated bacteria was from the gut in 16\% cases (Gram-negative bacilli, anaerobes), the ears, nose or throat for 23\% (Gram-positive streptococci and anaerobes) and skin for $61 \%$. To differentiate a significant bacteraemia from a contamination, the following criteria were proposed: type of bacteria, aerobes or anaerobes and growth rate. Nineteen blood cultures were thus found to be positive, nine were contaminations and two were indeterminate. All blood cultures with bacteria originating either from the ears, nose, throat or gut were considered as clinically relevant. None of these bacteria was held responsible for infection in the recipients.

\section{Organ donation refusal}

The family was present on site in $51 \%$ of cases. Death was declared on site in only 15 cases (24\%) while the possibility of organ donation was proposed 13 times (21\%). In all the other cases, this organ donation program was explained to the next of kin at our hospital. Among the 49 surrogate decision makers consulted for consent, 15 (31\%) denied permission for organ donation: 3 transmitted the dead person advanced directives, while 12 refused it in the absence of or contrary to the donor's directives. Finally, 14 families (25\%) were not consulted because of a contraindication to organ donation, a delay exceeding limits or failure to catheterise. Requests for permission of donation through the district attorney office in 25 NHBD (violent death) resulted in only 2 refusals. It was noteworthy that no refusal was recorded in the National Registry.

\section{Kidney retrieval and transplantation}

Twenty seven eligible NHBD (43\%) were finally retrieved (Figure 2). Among these 54 retrieved kidneys, 31 were transplanted and 23 kidneys were rejected mainly due to poor macroscopic appearance (4), positive HIV, HCV or HTLV serologies (8), venous thrombosis (1) or arterial dissection (2). Three out of the 4 rejected kidneys on account of poor macroscopic appearance had their 'twin' kidney transplanted with good results. In addition, eight kidneys were discarded because intra-renal vascular resistance was abnormally elevated during pulsatile perfusion.

Among the 31 kidney grafts, 24 were transplanted in our institution and could enter our follow up. There was a rate of delayed graft function of $92 \%$. The mean duration was $22 \pm 9$ days. Among these transplantations, three major complications led to graft loss: one untimely cessation of immunosuppressive therapy by the patient leading to acute rejection, one renal venous thrombosis with early graft removal, and one primary non function which may be related to longer warm ischaemia duration (185 minutes). The serum creatinine evolution is shown in Figure 3 for the remaining 21 patients. At three months, creatinine level was $162 \pm 69 \mu \mathrm{mol} / \mathrm{l}$ and $152 \pm 65$ $\mu \mathrm{mol} / \mathrm{l}$ at six months. Creatinine clearance at one month was $28 \pm 14 \mathrm{ml} / \mathrm{min}$, and $58 \pm 21$ and $66 \pm 24 \mathrm{ml} / \mathrm{min}$ at three and six months after transplantation, respectively $(n=22)$. Graft survival rate was $89 \%$ at three and six months.

Limited information was available through the Agence de la biomédecine for six out of the seven recipients transplanted elsewhere. For a follow-up period ranging from 6 to 12 months, graft survival rate was $100 \%$ and mean serum creatinine level was $135 \pm 53 \mu \mathrm{mol} / \mathrm{l}$.

\section{Discussion}

These data from uncontrolled NHBD showed that such a program was feasible in France and profitable in terms of successful organ transplantation. Indeed, even though only half of 


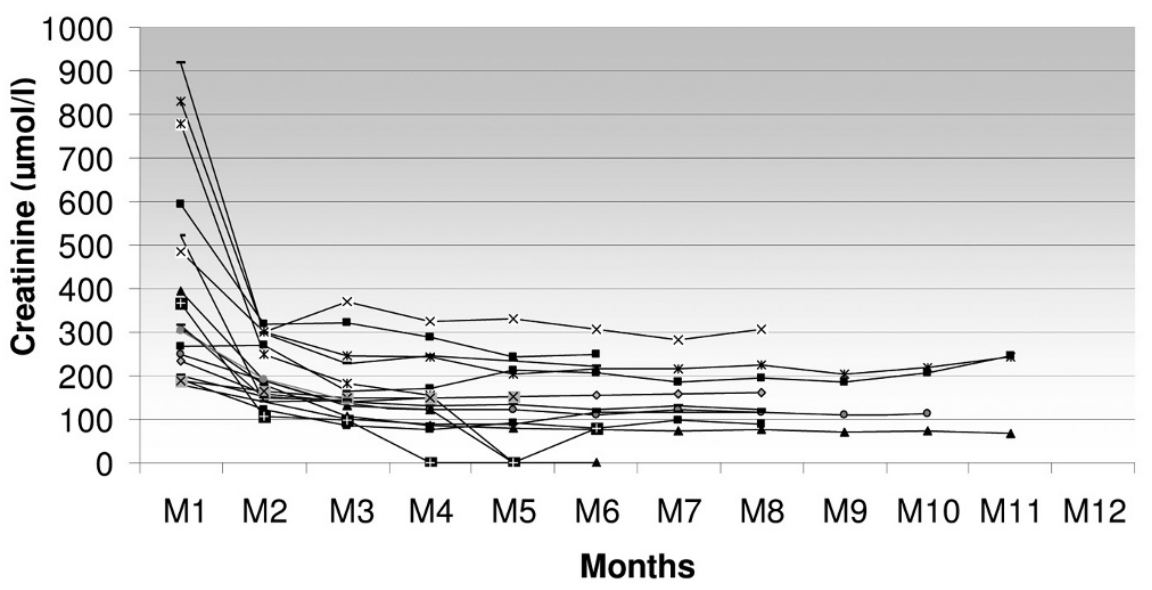

Serum creatinine individual evolution in the NHBD kidney recipients transplanted in the authors' institution $(n=21)$. Steady state creatinine level was obtained on average three months after transplantation. NHBD $=$ non heart beating donor.

the out-of-hospital cardiac arrests that were proposed could enter this program and only one-quarter had their kidneys actually retrieved, this program provided at least 27 successful renal transplants, including 21 carried out at our institution, within 17 months.

Renal transplantation remains the treatment of choice for patients with end-stage renal failure [16]. In 2007 in France, 2911 kidney grafts were provided by BDD for $90.6 \%$, by living donors for $8 \%$ and from NHBD for 1.4\%. In 2007, 128 patients died on the waiting list for kidney transplantation. To counter the shortage of grafts, an alternative source was organ harvesting from NHBD. This procedure, previously described in Europe, Japan and the USA [2,3,5,17], concerned mainly Maastricht 3 category NHBD. If harvesting controlled donors (withdrawal of care) provokes ethical controversies [18-20], 'uncontrolled donors' triggers many organisational problems.

In our institution, the initiation of this program proved satisfactory in many ways. On account of the very strong implication of the prehospital emergency services, an important cohort of potential NHBD was rapidly recruited. Hypothermia and poisoning were excluded because they had to receive an extracorporeal life support in accordance with the standard guidelines for CPR $[12,13]$. The admission rate was high, and during this first 17 months of activity we included more NHBD than expected when compared with other European centres trained in this procedure $[3,21,22]$. Few countries perform organ harvesting exclusively from 'uncontrolled donors' in Maastricht category 1 and 2 . In our institution, the on-duty critical care and surgical teams were in charge of this activity. However, only $8 \%$ of potential donors were refused because of organisational problems. During the study period, 31 kidney grafts were obtained from NHBD, 64 from BDD and 23 from living donors. Between 2006 and 2007, the transplantation rate increased by $10 \%$. This increase was not as important as expected from the literature $[19,23]$ because at the same time the incidence of BDD decreased for independent reasons.

The interview of potential organ donors' families is a legal requirement in France [6]. The National Registry did not yield any previous refusal, although this tool is only marginally used. We underwent a $32 \%$ rate of refusal and 15 potential donors were lost. This rate is in accordance with the national rate of refusal for BDD during 2007 (28\%) but much higher than in Spain (between 7\% [22] and 9.8\% [24]). The reasons for refusal were primarily related to religious aspects, the wish to maintain an intact body or socio-cultural barriers in minority groups, as previously described [25]. When the family was present during resuscitation attempts (51\%), the acceptance of death was easier. However, it was very difficult for the emergency team to discuss organ donation immediately after resuscitation as this could lead to confusion in the mind of the family.

Apart from family refusal, the transplantation rate was low: only $57.4 \%$ of the retrieved kidneys were transplanted, whereas in Spain the transplantation rate was more than $95 \%[3,22,26]$. There are some differences in their procedure: in Spain they use partial cardiopulmonary bypass machines with external oxygenation and hypothermia or normothermia [22], whereas we used regional cooling with the DBC. Our grafts were preserved ex vivo on a pulsatile perfusion machine. The protocol took into account elevated vascular resistance, which has been a significant source of kidney exclusion in our study (22\% retrieved kidneys). Sanchez-Fructuoso and colleagues [3] noticed that during their first 10 years of activity, they transplanted only $63 \%$ of their retrieved grafts of Maastricht type 1 and 2 donors. They used similar exclusion criteria except for high vascular resistance. In the future, the slope of the decreasing intrarenal resistance might also be considered for discarding organs. 
It seems that all the teams whose procedure was similar to ours (30 minutes maximum of no-flow duration, use of DBC) had a significant number of potential grafts being discarded. The discard rate for uncontrolled donors in England was estimated to range between 50 and 65\% [27]. Our final transplantation rate was $25 \%$ (63 potential NHBD/31 renal grafts).

The most critical issue in NHBD is the damage caused by prolonged warm ischaemia occurring between cardiac arrest and organ cooling. It results in delayed graft function or even in cortical necrosis leading to primary non function. In uncontrolled NHBD, warm ischaemia time may be difficult to assess [28]. The timings exceeded the limits fixed by the protocol in some donors: the duration between cardiac arrest and initiation of CPR exceeded 30 minutes in two donors (34 and 40 minutes). In some donors, the timing fixed by the protocol could not be strictly observed for several reasons. The causes were a long delay for the donor to be transferred to our hospital or a longer than expected procedure for intraaortic DBC insertion or for kidney retrieval. Interestingly, two discarded kidneys underwent histological examination at 158 minutes (rather than 150 minutes) of warm ischaemia and 225 minutes of time-to-retrieval (rather than 180 minutes). Both showed wellpreserved renal parenchyma with only moderate tubular necrosis.

Ischaemia occurring during kidney procurement is shorter in living donors and longer in cadaverous donors and NHBD, but has minimal influence on long-term graft survival [27]. Our primary non function rate was $3.2 \%$, similar to that found by other teams [3,4,27], including cohorts of 'controlled donors' [2]. The delayed graft function rate for NHBD transplants is higher than in heart beating donor (HBD) kidneys, and is more frequent in uncontrolled donors [21] than in controlled donors as illustrated by a greater incidence of acute tubular necrosis [29]. Patient survival and long-term graft function have been demonstrated to be equivalent in HBD and NHBD [2]. There is no difference for one year allograft survival and renal function is similar even after six years $[29,30]$. Thus, the high delayed graft function rate we observed (92\%) was in accordance with the literature concerning uncontrolled NHBD $[29,31]$. Creatinine plasma levels were equivalent to those found by other teams in uncontrolled donors $[3,31]$.

This procedure raised ethical controversies in France [32]. First, the question emerged about a conflict of interest between patient care and potential organ procurement. In this cohort, resuscitation duration was always longer than recommended. Secondly, to avoid any potential conflict of interest, there was a strict separation of roles between the care providers. The emergency physician in the SAMU ambulance independently considered the cardiac arrest to be irreversible and when to interrupt resuscitation manoeuvres. The intensivists were responsible for declaring death, approaching families while urologists and nephrologists dealt with recipient selec- tion, subsequent organ harvesting and transplantation. The third point was that the legislation allowed in situ organ preservation by the introduction of a cooling device before family information [6] as in other countries. The rationale was to shorten warm ischaemia and to offer more opportunities to contact families for organ donation.

Recently, some teams argued for extending indications of extracorporeal circulatory assistance for out-of-hospital refractory cardiac arrest, similarly to hypothermic or poisoned patients [33] or some specific intrahospital cardiac arrests [34-36]. Inclusion criteria in this procedure needs to be defined and investigated because its efficacy remains uncertain for patients with out-of-hospital cardiac arrests [35].

\section{Conclusions}

These data showed convincing results concerning kidney transplantation from NHBD. Strict adherence to the inclusion and exclusion criteria guarantees the long-term graft function. Although the rate of delayed graft function was almost $100 \%$, results at three and six months were satisfactory and similar to those obtained by other teams involved in similar programs. NHBD programs on uncontrolled donors are challenging for transplant coordination teams. The procedure is a coordinated effort with participation of out-of-hospital emergency services and hospital staff. There is, however, a need for a better acceptance of organ donation by the population, which could be obtained by sustained nationwide information campaigns. This would also allow the emergency teams to approach the family on site, screening for potential consent.

\section{Key messages}

- Patients dying from sudden out-of-hospital refractory cardiac arrests may be eligible to enter a highly standardised protocol of uncontrolled NHBD.

- This procedure elicited very different ethical issues compared with controlled Maastricht 3 donors (withdrawal of life sustaining therapy).

- Specific time and legal constraints of this emergency procedure implied a highly coordinated multidisciplinary teamwork in order to preserve organ function.

- Hypothermic pulsatile perfusion allowed prolonging ex vivo kidney resuscitation.

- Organ retrieval from uncontrolled NHBD may prove a valuable source of organs and is part of the answer to counter organ shortage, especially for the kidney.

\section{Competing interests}

The authors declare that they have no competing interests. 


\section{Authors' contributions}

FF contributed to the implementation of this new procedure, was involved in data collection and analysis, and drafted the manuscript. MRL contributed to the design of the study, was involved in data analysis, and drafted and revised critically the manuscript. EB, FB and OM contributed to the implementation of this new procedure and were involved in data collection of the NHBDs. FG participated in the implementation of this new procedure and was involved in kidney retrieval and transplantation. IA was involved in the care and data collection of graft recipients and helped to draft the manuscript. JLD was involved in the microbiological procedures and data collection. FR and FM contributed to the implementation of this new procedure and to data collection, and were heavily involved in the family interviews. FA participated to the implementation of this new procedure and actively participated in patient inclusions. $\mathrm{LJ}$ contributed to the implementation of the new procedure and study design, and drafted and revised the manuscript.

\section{Acknowledgements}

The authors are grateful to Dr. Kathleen McGee for editing this manuscript.

\section{References}

1. Agence de la Biomédecine: Rapport d'activité 2007: Bilan des activités de prélèvement et de greffe. [http://www.agencebiomedecine.fr].

2. Weber M, Dindo D, Demartines N, Ambuhl PM, Clavien PA: Kidney transplantation from donors without a heartbeat. $N$ Engl J Med 2002, 347:248-255.

3. Sanchez-Fructuoso Al, Prats D, Torrente J, Perez-Contin MJ, Fernandez C, Alvarez J, Barrientos A: Renal transplantation from nonheart beating donors: a promising alternative to enlarge the donor pool. J Am Soc Nephro/ 2000, 11:350-358.

4. Metcalfe MS, Butterworth PC, White SA, Saunders RN, Murphy GJ, Taub N, Veitch PS, Nicholson ML: A case-control comparison of the results of renal transplantation from heart-beating and non-heart-beating donors. Transplantation 2001, 71:1556-1559.

5. Kootstra G: Expanding the donor pool: the challenge of nonheart-beating donor kidneys. Transplant Proc 1997, 29:3620.

6. Assemblée Nationale: Décret $n^{\circ} \mathbf{2 0 0 5}-949$ du 2 Aout 2005 relatif aux conditions de prélèvements des organes, des tissus et des cellules. Journal Officiel de la République Française $n^{\circ} 182$, 6 August 2005 2005:12898.

7. Kootstra G, Daemen JH, Oomen AP: Categories of non-heartbeating donors. Transplant Proc 1995, 27:2893-2894.

8. Académie Nationale de Médecine: Comité d'Ethique. [http:// www.academie-medecine.fr].

9. Code de la Santé Publique: Loi de la Bioéthique article L 12321 and $L$ 1232-2. [http://www.legifrance.gouv.fr].

10. Gueugniaud PY, Mols P, Goldstein P, Pham E, Dubien PY, Deweerdt C, Vergnion M, Petit P, Carli P: A comparison of repeated high doses and repeated standard doses of epinephrine for cardiac arrest outside the hospital. European Epinephrine Study Group. N Engl J Med 1998, 339:1595-1601.

11. Adnet F, Dufau R, Roussin F, Antoine C, Fieux F, Lapostolle F, Chanzy E, Jacob L: Feasibility of out-of-hospital management of non-heart-beating donors in Seine-Saint-Denis: One year retrospective study. Ann Fr Anesth Reanim 2009, 28:124-129.

12. Société Française d'Anesthésie-Réanimation: Recommandations formalisées d'experts pour la prise en charge de l'arrêt cardiaque. [http://www.sfar.org].

13. ECC Committee, Subcommittees and Task Forces of the American Heart Association: American Heart Association guidelines for cardiopulmonary resuscitation and emergency cardiovascular care. Circulation 2005, 112:IV1-203.
14. Balupuri $S$, Buckley $P$, Snowden $C$, Mustafa $M$, Sen $B$, Griffiths $P$, Hannon M, Manas D, Kirby J, Talbot D: The trouble with kidneys derived from the non heart-beating donor: a single center 10year experience. Transplantation 2000, 69:842-846.

15. Gok MA, Buckley PE, Shenton BK, Balupuri S, El-Sheikh MA, Robertson H, Soomro N, Jaques BC, Manas DM, Talbot D: Long-term renal function in kidneys from non-heart-beating donors: a single-center experience. Transplantation 2002, 74:664-669.

16. Wolfe RA, Ashby VB, Milford EL, Ojo AO, Ettenger RE, Agodoa LY, Held PJ, Port FK: Comparison of mortality in all patients on dialysis, patients on dialysis awaiting transplantation, and recipients of a first cadaveric transplant. N Engl J Med 1999, 341:1725-1730.

17. Yoshida K, Endo T, Saito T, Iwamura M, Ikeda M, Kamata K, Sato $\mathrm{K}$, Baba S: Factors contributing to long graft survival in nonheart-beating cadaveric renal transplantation in Japan: a single-center study at Kitasato University. Clin Transplant 2002, 16:397-404.

18. Aulisio MP, Devita M, Luebke D: Taking values seriously: Ethical challenges in organ donation and transplantation for critical care professionals. Crit Care Med 2007, 35:S95-101.

19. Doig CJ, Rocker G: Retrieving organs from non-heart-beating organ donors: a review of medical and ethical issues. Can Anaesth 2003, 50:1069-1076.

20. Gardiner D, Riley B: Non-heart-beating organ donation - solution or a step too far? Anaesthesia 2007, 62:431-433.

21. Brook NR, White SA, Waller JR, Veitch PS, Nicholson ML: Nonheart beating donor kidneys with delayed graft function have superior graft survival compared with conventional heartbeating donor kidneys that develop delayed graft function. Am $J$ Transplant 2003, 3:614-618.

22. Sanchez-Fructuoso Al: Kidney transplantation from non-heartbeating donors. Transplant Proc 2007, 39:2065-2067.

23. Keizer KM, de Fijter JW, Haase-Kromwijk BJ, Weimar W: Nonheart-beating donor kidneys in the Netherlands: allocation and outcome of transplantation. Transplantation 2005, 79:1195-1199.

24. del Rio Gallegos F, Nunez Pena JR, Soria Garcia A, Moreno Roy MA, Varela A, Calatayud J: Non heart beating donors. Succesfully expanding the donor's pool. Ann Transplant 2004, 9:19-20.

25. Frutos MA, Blanca MJ, Ruiz P, Mansilla JJ, Seller G: Multifactorial snowball effect in the reduction of refusals for organ procurement. Transplant Proc 2005, 37:3646-3648.

26. Nunez JR, Del Rio F, Lopez E, Moreno MA, Soria A, Parra D: Nonheart-beating donors: an excellent choice to increase the donor pool. Transplant Proc 2005, 37:3651-3654.

27. Chaib E: Non heart-beating donors in England. Clinics 2008, 63:121-134.

28. Rela $M$, Jassem $W$ : Transplantation from non-heart-beating donors. Transplant Proc 2007, 39:726-727.

29. Gok MA, Asher JF, Shenton BK, Rix D, Soomro NA, Jaques BC Manas DM, Talbot $D$ : Graft function after kidney transplantation from non-heartbeating donors according to maastricht category. J Urol 2004, 172:2331-2334.

30. Sanni AO, Wilson $\mathrm{CH}$, Wyrley-Birch $\mathrm{H}$, Vijayanand D, Navarro $\mathrm{A}$, Gok MA, Sohrabi S, Jaques B, Rix D, Soomro N, Manaas D, Talbot D: Non-heart-beating kidney transplantation: 6-year outcomes. Transplant Proc 2006, 38:3396-3397.

31. Sanchez-Fructuoso A, Prats Sanchez D, Marques Vidas M, Lopez De Novales E, Barrientos Guzman A: Non-heart beating donors. Nephrol Dial Transplant 2004, 19(Suppl 3):iii26-31.

32. Comité d'éthique de la SRLF: Position de la société de réanimation de langue française (SRLF) concernant les prélèvements d'organe chez les donneurs à cœur arrêté. Réanimation 2007, 16:428-435.

33. Megarbane B, Leprince P, Deye N, Resiere D, Guerrier G, Rettab S, Theodore J, Karyo S, Gandjbakhch I, Baud FJ: Emergency feasibility in medical intensive care unit of extracorporeal life support for refractory cardiac arrest. Intensive Care Med 2007, 33:758-764.

34. Chen YS, Chao A, Yu HY, Ko WJ, Wu IH, Chen RJ, Huang SC, Lin FY, Wang SS: Analysis and results of prolonged resuscitation in cardiac arrest patients rescued by extracorporeal membrane oxygenation. J Am Coll Cardiol 2003, 41:197-203.

35. Chen YS, Yu HY, Huang SC, Lin JW, Chi NH, Wang CH, Wang $\mathrm{SS}$, Lin FY, Ko WJ: Extracorporeal membrane oxygenation sup- 
Critical Care Vol 13 No 4 Fieux et al.

port can extend the duration of cardiopulmonary resuscitation. Crit Care Med 2008, 36:2529-2535.

36. Massetti M, Tasle M, Le Page O, Deredec R, Babatasi G, Buklas D, Thuaudet S, Charbonneau P, Hamon M, Grollier G, Gerard JL, Khayat $A$ : Back from irreversibility: extracorporeal life support for prolonged cardiac arrest. Ann Thorac Surg 2005, 79:178-183. discussion 183-174 